\title{
Actualización: Hiperhidrosis
}

\author{
Hiperhidrosis
}

Noelia Cappellato $¥$ y Andrés D’ippolito

\begin{abstract}
Resumen
La hiperhidrosis es la producción excesiva de sudor que supera al fisiológicamente necesario para regular la temperatura corporal. Suele ser idiopática y afectar la vida social y laboral de quienes la padecen, siendo la localización palmar la forma más frecuente y problemática.

Su diagnóstico es eminentemente clínico y el abordaje terapéutico depende de su localización y de la repercusión que tenga en la vida del paciente. La primera línea de abordaje consiste en el tratamiento tópico con antitranspirantes que contengan hipoclorito de aluminio, reservándose para formas más graves la iontoféresis, los fármacos anticolinérgicos, la toxina botulínica y la simpatectomía.

Al final de este artículo se presenta una viñeta clínica de un paciente que plantea una duda de manejo, así como la estrategia utilizada para resolverla.

\section{Abstract}

Hyperhidrosis refers to the excessive production of sweat that exceeds the physiologically needed to regulate body temperature. It is usually idiopathic and affects both social and professional life of those affected individuals. The palms are the most common and troublesome affected site.

The diagnosis is eminently clinical and the therapeutic approach depends upon its location and its impact on the patient's life. Antiperspirants containing aluminum hypochlorite represent the first line of therapy, reserving iontophoresis, anticholinergic agents, botulinum toxin and sympathectomy for the most severe cases.

At the end of this article a clinical vignette of a patient with hyperhidrosis is presented, and a question of management and the strategy used to solve it is then posed.
\end{abstract}

sPalabras clave: hiperhidosis, toxina botulínica, tratamiento tópico. Key words: hyperhidrosis, botulinum toxin, topical treatments.

D'ippolito A. y Cappellato N. Hiperhidrosis. Evid Act Pract Ambul. 13(1).32-33. Ene-Mar 2010.

\section{Introducción}

La hiperhidrosis se define como la producción excesiva de sudor que supera al fisiológicamente necesario para mediar la termorregulación corporal'. Se trata de una patología frecuentemente observada en atención primaria. Su incidencia es desconocida aunque se cree que afectaría entre el 0,6 y el $3 \%$ de la población general.

Se estima que en la gran mayoría de los casos su origen es idiopático y en su patogenia se postula la existencia de una predisposición genética y étnica. Sin embargo, como existe una gran variabilidad individual en la cantidad de sudor producido ante determinado resulta difícil estimar cuando una secreción determinada es realmente patológica.

No existen estudios documentados sobre la historia natural de la enfermedad, aunque muchos expertos coinciden en que la gravedad de la hiperhidrosis disminuye hacia los 50 años de edad.

\section{Fisiopatogenia}

La sudoración generalizada se activa ante estímulos térmicos y está regulada por órdenes centrales provenientes del hipotálamo. Se cree que en estos pacientes existe cierta hipersensibilidad a estímulos hipotalámicos provenientes de la corteza cerebral y/o una estimulación anormal de las glándulas écrinas ${ }^{2}$. Sin embargo, las glándulas sudoríparas de ciertas áreas cutáneas como las palmas de las manos, las plantas de los pies, las axilas y la región craneofacial se muestran especialmente sensibles a estímulos emocionales.

\section{Manifestaciones clínicas}

Los pacientes con hiperhidrosis idiopática $(\mathrm{HI})$ generalmente desarrollan manifestaciones durante la niñez y adolescencia, que pueden permanecer hasta la vida adulta y ocurren funda- mentalmente en las palmas, las plantas y las axilas.

Desde el punto de vista social y laboral, la hiperhidrosis palmar es la forma más frecuente y problemática, cuyas formas graves suelen asociarse a frialdad y palidez en los dedos.

La forma plantar determina humedad, maceración y predisposición a infecciones fúngicas y bacterianas. La presencia de sudoración excesiva a nivel de las axilas hace que la piel esté mojada, usualmente traspasando hasta la ropa.

Frecuentemente, a esta situación se añade la bromhidrosis u olor desagradable del sudor, originado por la descomposición del sudor y de los restos de células descamadas de la piel por parte de bacterias y hongos del sudor. No es difícil entonces imaginarse el problema social que impone la hiperhidrosis, al alterar la imagen corporal del paciente.

\section{Diagnóstico}

El diagnóstico de la hiperhidrosis eminentemente clínico ${ }^{3}$, enumerándose sus criterios diagnósticos en el cuadro 1.

Cuadro 1: criterios diagnósticos de hiperhidrosis idiopática. Sudoración focal, visible y excesiva de al menos seis meses de evolución sin una causa aparente, acompañada de al menos dos de las siguientes características:

a. Manifestación bilateral y simétrica.

b. Malestar en la realización de actividades diarias.

c. Al menos un episodio de sudoración profusa por semana.

d. Comienzo antes de los 25 años.

e. Historia familiar de hiperhidrosis.

f. Las manifestaciones locales se detienen durante el sueño.

Sin embargo, existen varias técnicas utilizadas en algunos casos por los especialistas:

Técnicas calorimétricas, o prueba del yodo-almidón: son las 
más utilizadas y consisten en impregnar la superficie de la piel con una tintura alcohólica de yodo al $2 \%$ que una vez seca, se espolvorea con almidón. Su mezcla con el sudor decolora el yodo, lo que permite identificar visualmente las gotas de sudor como puntos azulados marronáceos en la piel, que indican la localización de las glándulas sudoríparas secretoras.

Técnicas evaporimétricas: se utilizan para evaluar la tasa o volumen de sudoración, basándose en los cambios de presión parcial de vapor de agua en una cámara cerrada.

Técnicas electrofisiológicas: miden los cambios en la resistencia eléctrica de la superficie cutánea debidos a la actividad secretora de las glándulas sudoríparas.

\section{Diagnósticos diferenciales}

En mujeres adultas, la perimenopausia puede estar implicada en las molestias que refiere la paciente. Por otro lado, la sudoración excesiva generalizada puede ser secundaria a enfermedades infecciosas, endocrinas o neurológicas, y también a efectos adversos de ciertos medicamentos como antidepresivos tricíclicos, inhibidores de la recaptación de la serotonina, antimigrañosos (triptanes) y sulfonilureas.

Cuando las manifestaciones clínicas comienzan durante la etapa adulta deberían evaluarse causas secundarias de sudoración: infección por el virus de la inmunodeficiencia humana (VIH), endocarditis, neoplasias (sobre todo linfomas) y endocrinopatías (como síndrome carcinoide, feocromocitoma o hipertiroidismo).

Otras causas menos frecuentes de hiperhidrosis se relacionan a injurias en el cordón espinal (disreflexia autonómica).

\section{Tratamiento}

El tratamiento se deberá adaptar a cada caso en particular de acuerdo a su severidad, localización y alteración social del paciente ${ }^{4}$.

Las terapéuticas actuales tópicas suelen ser efectivas en ciertos casos y se consideran de primera línea. Así, en los casos leves, los antitranspirantes con hipoclorito de aluminio comercializados en forma de pomadas y "roll-on". Algunas presentaciones además contienen antibióticos tópicos para evitar la bromhidrosis. Presentan como desventajas su costo relativa- mente elevado y el riesgo de irritación local. Se aplican de noche sobre la piel limpia y seca, y el mecanismo de acción sería la oclusión del conducto de las glándulas sudoríparas. La iontoféresis o iontoforesis con agua corriente puede resultar eficaz en la afectación palmoplantar. El tratamiento se realiza entre tres a seis sesiones semanales durante 30 minutos. Los resultados dependen de las dosis empleadas y son limitados en el tiempo. El mecanismo de acción estaría dado por el reposo temporal de las glándulas a partir del paso de la corriente eléctrica.

Además de otros efectos adversos desagradables, los fármacos anticolinérgicos producen hipohidrosis, por lo que en ocasiones pueden ser considerados como estrategia terapéutica, siendo el glucopirrolato y la oxibutinina son los más utilizados. Existen terapias sistémicas utilizando medicación ansiolítica (benzodiacepinas) o antidepresiva, que pueden emplearse cuando los síntomas están directamente relacionados con el estrés emocional.

Recientemente, se ha incorporado a la terapéutica la toxina botulínica $\mathrm{A}(\mathrm{BTX}-\mathrm{A})^{5}$. La inyección en las áreas hiperhidróticas reduce considerablemente la sudoración local sin efectos adversos mayores. El mecanismo de acción es el bloqueo de las terminaciones nerviosas que causan el estímulo a las glándulas sudoríparas. Se considera el tratamiento de elección para la hiperhidrosis axilar que no responde a la terapia tópica. Las desventajas de este tratamiento incluyen su alto costo y la reversibilidad del efecto a los pocos meses, en general cerca de los tres meses para las palmas y los ocho meses para las axilas.

La simpatectomía ${ }^{6}$ es una técnica quirúrgica que se reserva como última opción terapéutica y principalmente para la hiperhidrosis palmar y/o plantar severa que no responde al tratamiento tópico convencional. Las complicaciones de este tratamiento son múltiples, ya que además de los riesgos de la cirugía, se puede observar sudoración compensatoria -sudoración excesiva en otras partes del cuerpo no afectadas previamente- alteración del gusto, neumotórax, neuralgias intercostales, síndrome de Horner y recurrencia de la hiperhidrosis. Existen técnicas quirúrgicas más modernas como la simpaticólisis videoendoscópica bilateral a nivel de los ganglios D2D4, que se considera en general definitiva, con una baja tasa de complicaciones y alta efectividad, siendo la de elección en la actualidad en los casos refractarios.

\section{Referencias}

1. Smith C. Idiopatic Hyperhidrosis. In: UpToDate, Rose, BD (Ed). UpToDate, Waltham MA, 2009.

2. Grimalt R y col, editores. Hiperhidrosis. Diagnóstico actual y tratamiento. $1^{\mathrm{a}}$ ed. Madrid: Médica Panamericana; 2004.

3. Hornberger $\mathrm{J}$ y col. Recognition, diagnosis and treatment of primary focal hyperhidrosis. J Am Acad Dermatol 2004;51:274-86.

4. Eisenach J y col. Hyperhidrosis: evolving therapies for a well-established phenomenon. Mayo Clin. Proc. 2005;80:657-66.

5. Grunfeld A y col. Botulinum toxin for hyperhhidrosis: a review. Am. J. Clin. Dermatol 2009;10(2):87-102.

6. Yano M y col. Endoscopic thoracic sympathectomy for palmar hyperhydrosis: efficacy ganglion resection. Surgery 2005;138(1):40-5. 